\title{
Commentary: Echocardiographic Evaluation of Pulmonary Pressures and Right Ventricular Function after Pediatric Cardiac Surgery: A Simple Approach for the Intensivist
}

\author{
Stefan Kurath-Koller*, Sabrina Schweintzger and Martin Köestenberger \\ Division of Pediatric Cardiology, Department of Pediatrics, Medical University Graz, Graz, Austria
}

Keywords: PAH, pediatrics, RV function, echocardiography, critical care

\section{A commentary on}

\section{OPEN ACCESS}

Edited by:

Giovanni Biglino,

University of Bristol, United Kingdom

Reviewed by:

Joan Sanchez-de-Toledo, Hospital Sant Joan de Déu Barcelona,

Istituto Giannina Gaslini (IRCCS), Italy

${ }^{*}$ Correspondence:

Stefan Kurath-Koller

stefan.kurath@medunigraz.at

Specialty section:

This article was submitted to

Pediatric Cardiology,

a section of the journal

Frontiers in Pediatrics

Received: 31 January 2018

Accepted: 24 April 2018

Published: 08 May 2018

Citation:

Kurath-Koller S, Schweintzger S and

Köestenberger M (2018)

Commentary: Echocardiographic Evaluation of Pulmonary Pressures and Right Ventricular Function after Pediatric Cardiac Surgery: A Simple Approach for the Intensivist.

Front. Pediatr. 6:136.

doi: 10.3389/fped.2018.00136
Echocardiographic Evaluation of Pulmonary Pressures and Right Ventricular Function after Pediatric Cardiac Surgery: A Simple Approach for the Intensivist

by Beghetti, M. (2017). Front. Pediatr. 5:184. doi: 10.3389/fped.2017.00184

A recent multicenter analysis in pediatric intensive care units shows, that despite of therapeutic advances, the disease burden and mortality of children with pulmonary arterial hypertension (PAH) remains significant (1). This calls into attention a recent Review by in Frontiers in Pediatrics which we read with great interest. The article "Echocardiographic Evaluation of Pulmonary Pressures and Right Ventricular Function after Pediatric Cardiac Surgery: A Simple Approach for the Intensivist" by Beghetti (2) describes an extremely useful overview how to use an echocardiography approach to quickly evaluate pulmonary arterial pressure (PAP) and right ventricular (RV) function in children in regard of PAH in the intensive care unit setting. The author elaborates that in this population there is a clear need for a thoroughly evaluation of children with an "RV under pressure," using the first line investigation echocardiography (2). Children with PAH still are challenging in regard of evaluation and treatment (3).

This land marking echocardiographic approach of Beghetti uses direct and indirect echocardiographic measurements including the commonly used tricuspid regurgitant (TR) jet velocity, pulmonary regurgitation (PR) jet (used to calculate the mean PAP and diastolic PAP), $\mathrm{D}$-shaping of the left ventricle (LV), the LV eccentricity index, right ventricular fractional area change (RVFAC), tricuspid annular plane systolic excursion (TAPSE), and tissue Doppler imaging (TDI) parameters. This approach is in parts in agreement with recent US and European pediatric PAH guidelines (4-6). To date, in our intensive care unit (ICU) we use calculation of the TR jet, the PR jet, the pulmonary artery acceleration time (PAAT), the tricuspid annular peak systolic velocity (TDI), and the tricuspid annular plane systolic excursion (TAPSE) measurements to quickly investigate RV function and pressure in postoperative patients. We completely agree with the author (2) that pulmonary vascular resistance (PVR) is too complex to measure in critical care medicine when a quick evaluation is needed and furthermore that more detailed/complex measurements such as TEI index, strain measurements, and 3D measurements are way too time consuming in this specific setting.

Due to the convincing approach of Maurice Beghetti will from now follow this approach in our ICU. 
Currently there is an ongoing discussion on the indication/need for cardiac catheterization in children with suspected PAH (7). If properly performed, echocardiography may make cardiac catheterization expandable in the immediate postoperative period (7), taking into account the critical condition of these patients and potential complications (8).However, cardiac catheterization still remains the gold standard for the diagnosis of a PAH (8). In addition we agree with the notice of Beghetti (2) that more data of treatment strategies for pediatric PAH, although partially existing $(9,10)$, are highly recommended.

We want to thank the author for addressing the need for quick, simple, and reproducible measurements in children with suspected PAH and/or RV dysfunction for the intensivist and want to highlight his article, which now provides essential tools

\section{REFERENCES}

1. Balkin EM, Steurer MA, Delagnes EA, Zinter MS, Rajagopal S, Keller RL, et al. Multicenter mortality and morbidity associated with pulmonary hypertension in the pediatric intensive care unit. Pulm Circ. (2018) 8:2045893217745785. doi: $10.1177 / 2045893217745785$

2. Beghetti M. Echocardiographic evaluation of pulmonary pressures and right ventricular function after pediatric cardiac surgery: a simple approach for the intensivist. Front Pediatr. (2017) 5:184. doi: 10.3389/fped.2017.00184

3. Beghetti M, Berger RM. The challenges in paediatric pulmonary arterial hypertension. Eur Respir Rev. (2014) 23:498-504. doi: 10.1183/09059180.00007714

4. Hansmann G, Apitz C. Treatment of children with pulmonary hypertension. Expert consensus statement on the diagnosis and treatment of paediatric pulmonary hypertension. The European Paediatric Pulmonary Vascular Disease Network, endorsed by ISHLT and DGPK. Heart (2016) 102(Suppl. 2), ii67-85. doi: 10.1136/heartjnl-2015-309103

5. Geerdink LM, Bertram H, Hansmann G. First-in-child use of the oral selective prostacyclin IP receptor agonist selexipag in pulmonary arterial hypertension. Pulm Circ. (2017) 7:551-4. doi: 10.1177/2045893217703369

6. Abman SH, Hansmann G, Archer SL, Ivy DD, Adatia I, Chung WK, et al. Pediatric Pulmonary Hypertension: Guidelines from the American Heart Association and American Thoracic Society. Circulation (2015) 132:2037-99. doi: 10.1161/CIR.0000000000000329

7. Beghetti M, Berger RM, Ivy DD, Bonnet D, Humpl T. To "Cath" or Not in Pediatric Pulmonary Hypertension? J Am Coll Cardiol. (2016) 67:1010-1. doi: 10.1016/j.jacc.2015.11.056 to acquire this target (2). It would be of benefit for the audience of Frontiers in Pediatrics if doctor Beghetti would be willing to provide a simple Table/Figure with the few variables to quickly measure RV function and PAH estimation-as a short survey for intensivists all over the world. With this remarkable approach, we are convinced that in near future the evaluation and decision making on potential PAH or RV dysfunction therapy will be more easily feasible in postoperative congenital heart disease children. Beyond this, we recommend this approach to every ICU physician.

\section{AUTHOR CONTRIBUTIONS}

All authors listed have made a substantial, direct and intellectual contribution to the work, and approved it for publication.

8. Beghetti M, Schulze-Neick I, Berger RM, Ivy DD, Bonnet D, Weintraub RG, et al. Haemodynamic characterisation and heart catheterisation complications in children with pulmonary hypertension: Insights from the Global TOPP Registry (tracking outcomes and practice in paediatric pulmonary hypertension). Int J Cardiol. (2016) 203: 325-30. doi: 10.1016/j.ijcard.2015.10.087

9. Hansmann G, Apitz C, Abdul-Khaliq H, Alastalo TP, Beerbaum P, Bonnet D, et al. Executive summary. Expert consensus statement on the diagnosis and treatment of paediatric pulmonary hypertension. The European Paediatric Pulmonary Vascular Disease Network, endorsed by ISHLT and DGPK. Heart (2016) 102(Suppl. 2):ii86-100.

10. Berger RMF, Gehin M, Beghetti M, Ivy D, Kusic-Pajic A, Cornelisse P, et al. A bosentan pharmacokinetic study to investigate dosing regimens in paediatric patients with pulmonary arterial hypertension: FUTURE-3. Br J Clin Pharmacol. (2017) 83:1734-44.

Conflict of Interest Statement: The authors declare that the research was conducted in the absence of any commercial or financial relationships that could be construed as a potential conflict of interest.

Copyright (c) 2018 Kurath-Koller, Schweintzger and Köestenberger. This is an openaccess article distributed under the terms of the Creative Commons Attribution License (CC BY). The use, distribution or reproduction in other forums is permitted, provided the original author(s) and the copyright owner are credited and that the original publication in this journal is cited, in accordance with accepted academic practice. No use, distribution or reproduction is permitted which does not comply with these terms. 